$2 \mathrm{P}-160$ ミオシンは単分子より多分子の方がエネルギ一消費を節約できる のはなぜか

Why the energy consumption of myosin can be reduced when they work together? Takeshi Nakagawa (1), Hiroto Tanaka (2), and Kazuo Sasaki (1). (1: Dept. of Applied Physics, Tohoku Univ.; 2: PRESTO, JST

It is curious that the distance one myosin interacting with the actin filament moves by the consumption of 1 ATP (the interaction-length, IL) is found to be $5-15 \mathrm{~nm}$ and $60-200 \mathrm{~nm}$ in the experiment of single and multiple myosins, respectively. At the last annual meeting one of us (HT) suggested a model of multiple myosin molecules which are connected with springs and move on a two-dimensional chemo-mechanical potential surface (BSJ 2007). It was demonstrated that IL of multiple myosins is longer than that of single myosin. Due to the complexity of the potential, we cannot intuitively understand the mechanism underlying such behavior of multiple myosins.

To understand the mechanism it would be worth constructing a simpler model that captures the essence of the above model. We have succeeded to construct ratchet model which shows longer IL for multiple myosins than that for a single myosin. This model will allow us to gain insight into why the energy consumption per unit distance of a myosin in multiple myosin system can be lower than that of one myosin.

2P-161 キネシンの協調的な二足歩行運動に対するネックリンカーの役割

Role of the neck linker on the coordinated processive movement of kinesin dimer Hiroshi Isojima(1),Yuji Toyokita(1),Teppei Mori(1)and Michio Tomishige(1).(1:Department of Applied Physics, The University of Tokyo)

Kinesin is a motor protein that is involved in intracellular transport, and has recently been shown to walk along microtubules by alternately moving two motor 'heads'. Such processive movement requires a mechanism for coordination between two heads, and to explain this mechanism a model has been proposed that internal tension built up through the neck linker is essential for the head-head communication. To test this idea, we reduced the tension posed to the neck linker by extending the neck linker using poly-Gly insertions and observed conformational states of these mutants using single-molecule fluorescence resonance energy transfer. Under low nucleotide (ADP) conditions, where wild-type kinesin is known to take one-head-bound state, the neck linker extended mutants stably took two-head-bound state. We also found that in this state the neck linkers in the two heads extended rearward and took similar conformations. These neck linker conformations are distinct from those observed for wild-type kinesin in two-head-bound state whose neck linkers in front and rear heads poin rearward and forward respectively. These results suggest that the optimal size of the neck linker is important for maintaining the opposite geometry of the two neck linkers, which might be involved in the head-head coordination.

\section{P-162 走査プローブと光ピンセットの実験結果の相違を説明するミオシ} ンの運動モデル

Construction of myosin model explaining difference between experimental results observed with scanning probe and optical tweezers.

Hiroto Tanaka. (PRESTO, JST)

Single molecule measurement (SMM) techniques have been applied to myosin Then, SMMs' results show that, during single ATP hydrolysis cycle, myosins II \& $\mathrm{V}$ repeat several cycles of association with- and dissociation from an actin filament to generate sliding motion, suggesting that myosin can convert ATP energy by multi-step processes (MSPs). This MSPs cannot be explained by conventional "lever-arm model", then "Biased Brownian motion (BBM) model" has been proposed for a mechanism of myosin. However, the MSPs have been observed only by SMM with scanning probe (SP), and not observed with optical tweezers (OT) widely used for SMM. Because MSPs have been observed clearly with myosin II \& V, it is strongly suggested that BBM is movement mechanism of myosin. Then, why have MSPs not been observed with optical tweezers? In order to answer this question, here, we construct model including characteristics of SP $\&$ OT, and simulate movement of myosin attached to measurement probes (SP or OT). Taking into account the effects of measurement probes, we construct 2-dementional potential along an actin filament, and simulate movement of myosin on the 2D potential by Monte Carlo method. For simulation, spring constants of probes parallel and perpendicular to an actin filament are set according to characteristics of each probe. As a result, sliding velocity with SP $(\sim 0.5 \mu \mathrm{m} / \mathrm{s})$ becomes slower than that with OT $(\sim 3 \mu \mathrm{m} / \mathrm{s})$, then MSPs are clearly observed with SP. This result explains well the experimental results with SP and OT.

2P-163 一分子 FRET を利用した $\mathrm{F}_{1}-\mathrm{ATPase}$ の触媒サブュニット $\beta$ の構造変 化の検出

Detection of conformational changes of the $\beta$ subunits in F $_{1}$-ATPase by FRET

Masaru KOBAYASHI(l), Takayuki NISHIZAKA(l), Tomoko MASAIKE(l).(l:Department of Physics, Gakushuin University)

$F_{1}$-ATPase is a rotary molecular motor in which the central $\gamma$ subunit rotates against hexagonally arranged $\alpha_{3} \beta_{3}$ subunits. Rotation of the $\gamma$ is assumed to be driven by conformational changes of the catalytic $\beta$ subunits during ATPase turnover. Changes in orientation of the C-terminal domain of $\beta$ against the $\mathrm{N}$-terminal domain during rotation of $\gamma$ have been detected by the polarization modulation system (Masaike et al., 45th Biophysical Society Meeting of Japan,
2007). To reveal the mechanism of driving rotation from the viewpoint of inter-subunit distances of domains, we have applied fluorescence resonance energy transfer (FRET) method to measure changes in absolute distance between fluorescent molecules attached to $\mathrm{C}$-terminal residues of two different $\beta$. Cysteines were introduced into $\mathrm{C}$-terminal domain of the $\beta$ and labeled with either Cy3- or Cy5-maleimide.

Inter-subunit FRET between Cy3 and Cy5 attached to different $\beta$ in the $\alpha_{3} \beta_{3} \gamma$ was detected by spectrofluorometer. To reveal the relationship between stepwise changes in FRET efficiency and rotation of the $\gamma$, we developed an optical system for simultaneous detection of $\mathrm{Cy} 3$ and $\mathrm{Cy} 5$. Alternate-stepwise intensity changes of Cy 3 and $\mathrm{Cy} 5$ were observed under a fluorescence microscope. Additionally, in the present system, the micro beads attached to the $\gamma$ subunit is simultaneously monitored in another wavelength. New mutants will be designed and tested if larger changes in FRET efficiencies are observed using a spectrophotometer and also under the microscope at the single molecular level.

\section{P-164 負荷存在下でのキネシンの構造状態の一分子 FRET 観察}

Single molecule FRET observation of the conformational state of kinesin under load

Shota Kobashigawa(1), Michiko Nakajima(1), and Michio Tomishige(1) (1: Dept. of Applied Physics, School of Engineering, Univ. of Tokyo)

Kinesin is a motor protein that converts chemical energy derived from ATP hydrolysis to the mechanical work to move processively along microtubules. Optical trapping studies showed that the velocity is reduced as the external load applied to kinesin increases. However, it is still unknown which conformational transition in ATP hydrolysis cycle is the load-dependent step. Last year, we reported that using rapamycin-FK506 binding protein (FKBP) crosslinking system we crosslinked two kinesin dimers and observed the movement of this kinesin complex along microtubules. In this study, we replaced one of the two crosslinking kinesins by a mutant kinesin that tightly binds and cannot detach from the microtubule. Then we used this complex to apply load to the other wild-type kinesin dimer and observed its conformational state on the microtubule using single molecule fluorescence resonance energy transfer technique. We found that at saturating ATP concentration, the wild-type kinesin spent most of the time in one-head-bound state, which is clearly distinct from the configuration of wild-type kinesin before crosslinking that spends most of the time in two-head-bound state. These results suggest that the transition from one- to two-head-bound state might be prohibited under high load.

\section{P-165 分子モータの逐次性に関する理論的研究}

Theoretical study of processivity of double-headed molecular motors

Noriko Tsuchiyama and Takahiro Harada. (Department of Human and Artifical Intelligent Systems, University of Fukui)

For linear processive motors such as kinesin, processivity is one of the most important functions. By experimental studies on various motors, the relations of processivity to a molecular structure and to environmental parameters have been reported.In order to clarify the factors affecting prosocessivity of a molecular motor, construction of a simple mathematical model is highly important, because we can survey wide range of parameters with a relative ease. This enables us to study the general properties of linear processive motors on the basis of the mathematical model. However, a satisfactory model to explain existing experimental data has not been presented.Here, we studied processivity of linear processive motors by constructing a simple mathematical model. In order to take a detachment of a motor into consideration, we constructed a two dimensional model by extending a flashing ratchet model. Moreover, the motor was made double-headed by elastically coupling two heads.As a result, we confirmed that this model can make a sliding motion in a hand-over-hand fashion. Furthermore, it was found that the dependence of the run length on ligand concentrations in this model is consistent with the previous observations for kinesin. As a next step, we will examine whether this model can successfully explain the experimentally observed dependence of processivity on other parameters including the temperature and the magnitude of a load.In the presentation, we report the detail of our numerical investigation of this mathematical models.

\section{P-166 |I 型トポイソメラーゼが手品のようにDNAの絡まりを解くところ を一分子操作 ·観察する}

Single-molecule observation of unlinking magic by type-II topoisomerases with real-time control of DNA substrates

Katsunori Yogo(1), Taisaku Ogawa(1), Saki Obata(1) and Kazuhiko Kinosita Jr(1). (1: Dept. of Phys., Grad. School of Science and Engineering, Waseda Univ.

Type-II DNA topoisomerases (topoII) are molecular machines that play key roles in the maintenance of DNA topology in cells. They control the degree of supercoiling of DNA and untangle the catenanes that arise during replication or recombination. Lack of their activities during cell division ultimately causes cell death. TopoII untangles DNA catenanes in an ATP-dependent manner, by catalyzing the transport of one DNA segment to the other side of a second DNA segment through a transient double-stranded break in the second segment. The work of topoII would seem like that of a magician who fascinates the audience. We developed the system that enables us to observe directly this unlinking magic under an optical microscope. Single-molecules of DNA are fixed on chamber surface and mechanically braided with dual optical tweezers. One of the advantages of this method against bulk assay is that we can control geometry and tension in the DNA braid in real time and observe unlinking reaction repeatedly 
for exactly the same substrates. We measured unlinking rate of topoII and examined its dependence on the geometry and tension in DNA. Chiral preference for left- or right-handed DNA braid is also studied.

\section{P-167 アクチン分子内ダイナミクスの解明を目指した部位特異的 1 分子} FRET 計測

Site-directed single molecule FRET measurement to clarify the intra molecular dynamics of actin

Masatoshi Morimatsu (1), So Nishikawa (1), Mitsuhiro Sugawa (1), Atsuko H Iwane (1) and Toshio Yanagida (1). (1: Graduate School of Frontier Biosciences, Osaka University)

Actin forms a dynamic polymeric network on which motor protein myosin $\mathrm{V}$ transports vesicles. Do actin filaments act as a just passive rail for myosin movements or a positive rail for activating them? Recently it has been reported using single molecule FRET measurement that actin in the filament has dynamic conformational change between active and inactive states in the time scale of second. In this study, we tried to confirm this conclusion using a different pair of dyes after improvement of the microscopy. Glutamate 41 of actin is substitutated to Cystein residue transgenically for site-directed labeling by SH-group reactive fluorescent dyes (Alexa555, Alexa647) in addition to Cystein 374. As a result, the distance between Cys 41 and Cys 374 was $5.4 \mathrm{~nm}(\mathrm{SD}=0.4 \mathrm{~nm})(\mathrm{N}=335$ molecules $)$ in the absence of myosin from the histogram data of the single molecule FRET result. Next we focused on the relationship between the distance and the number of myosin $\mathrm{V}$ existing on the filament at $1 \mathrm{mM}$ ATP. At $\sim 0.4 / 1 \mathrm{pitch}$ (Myosin/ 72 $\mathrm{nm})$ the distance was $5.4 \mathrm{~nm}(\mathrm{SD}=0.38 \mathrm{~nm}) \quad(\mathrm{N}=195$ molecules $), \quad 5.4$ $\mathrm{nm}(\mathrm{SD}=0.37 \mathrm{~nm})$ at $\sim 0.05 / 1$ pitch $(\mathrm{N}=209$ molecules). We did not detect dynamic conformational change because photo bleaching time of the acceptor was short (mean $\sim 3 \mathrm{sec}$ ). We have further improved the observation time by using time-raps imaging system and scavenger. We will report our latest achievements at the time of the meeting.

\section{P-168 解離駆動機構に基づくキネシンのシミュレーションモデル}

A simulational model of a conventional kinesin based on the Driven by Detachment mechanism

Tadashi Masuda (School of Biomedical Science, Tokyo Medical and Dental Univ)

Although the core structure of kinesins is similar to that of myosins, no unified mechanism for the workings of these molecular motors has been proposed. In particular, the lever-arm hypothesis, which is widely considered to explain the behavior of myosins, cannot be applied directly to kinesins. I have proposed a mechanochemical process named "Driven by Detachment (DbD)" mechanism to explain characteristic behaviors of myosins, which include the backward movement of the myosin VI and the loose coupling phenomenon of the myosin II. The DbD mechanism assumes that the energy of ATP is solely used to detach a myosin from an actin filament by temporarily reducing the affinity of a myosin against an actin. After the affinity is recovered, a myosin has potential energy originating from the attractive force between a myosin and an actin. During the docking process, the potential energy is converted into elastic energy within a myosin molecule, and the elastic energy is finally used to conduct mechanical work of power strokes. For the model of the conventional kinesin, the neck linker was assumed to be a structure that was passively detached from and attached to the catalytic core independent of the nucleotide state Under this assumption, simple simulations showed that the model of a dimeric kinesin moved processively along the microtubule by controlling the affinity of a kinesin against a tubulin. Moreover, if external force was applied to the center of the kinesin dimer, the kinesin moved backward along the microtubule.

\section{P-169 蛍光共鳴エネルギ一移動法を用いた pPDM 架橋骨格筋ミオシンの 構造解析}

Analysis of Conformation of the pPDM Crosslinked Skeletal Muscle Myosin Using FRET.

Masafumi D. Yamada (1), Eisaku Katayama (2), Shinsaku Maruta (1).(1:Department of Bioinformatics, Faculty of Engineering, Soka University; 2:Division of Biomolecular Imaging, Institute of Medical Science, The University of Tokyo)

Previously biochemical studies have demonstrated that the highly reactive cysteine residues $\mathrm{SH} 1$ and $\mathrm{SH} 2$ can be crosslinked by variety of bifunctional reagents with different spans (3-14 $\AA$ ) in the presence of nucleotides, suggesting that the region is highly flexible. The $\mathrm{SH} 1-\mathrm{SH} 2$ region is believed to play a key role in the conformational changes that occur in the myosin head during the force generation coupled to ATP hydrolysis. We have previously shown that the HMM, which SH1-SH2 was crosslinked by p-Phenylene-dimaleimide (pPDM) in the presence of ADP, have a novel conformation using quick freeze deep etch electron microscopy (QFDE-EM). We have also demonstrated that conformational change of the myosin motor domain during ATP hydrolysis can be monitored by measuring the FRET using fluorescent ATP analogue NBD-ATP. In the present study, we analyzed the conformation of the myosin crosslinked by pPDM using FRET between the ATP binding site and the Al essential light chain (ELC). We prepared skeletal muscle myosin subfragment-1 (S1), which ELC was labeled by 6-bromoacetyl-2-dimethylaminonaphthalene (BD) at the Cys 177. And fluorescent ADP analogue NBD-ADP was trapped in the ATPase site of BD labeled S1. The FRET efficiency was estimated by measuring the change of fluorescence intensity of BD comparing with control BD-S1. FRET efficiency of pPDM-S1-NBD-ADP was lower than S1-NBD-ADP state. This suggests that the pPDM-S1-ADP forms more straight conformation an S1-ADP state in the ATP hydrolysis cycle.
2P-170 新規イネキネシン L05, D04 の NBD-ATP による速度論的解析

Kinetic characterization of the novel rice kineisn L05 and D04 using fluorescent ATP analogue.

Nozomi Umezu (1), Yuko Kubo (1) Kazunori Kondo (2) Toshiaki Mitsui (3) and Shinsaku Maruta (1,2). (1: Division of Bioinformatics, Graduate School of Engineering, Soka University, 2: Dept. of Bioinformatics, Faculty of Engineering, Soka University, 3: Graduate
School of Science and Technology, Niigata University)

Kinesin is an ATP driven motor protein that plays important physiological roles in intracellular transport, mitosis and meiosis, control of microtubule dynamics and signal transduction. Kinesins derived from vertebrate have been well studied on their characterization. However, not so many studies for kinesins of plants have been done yet. Previously, we have expressed the novel rice kinesin K16 by E.coli. Biochemical and crystallographic studies of the K16 motor domain demonstrated that $\mathrm{K} 16$ has very unique characterization and conformation, which may reflect the plant specific physiological role. We have also succeeded to express other several rice kinesins. In this study, we focused on rice specific kinesin D04 and L05. The kinesin motor domains of D04 and L05 are found at the N-terminal. In our preliminary search, D04 and L05 belonged to kinesin-4 sub family and kinesin-7 (CENP-E) sub family each. Kinetic characterizations of the kinesin D04 and L05 motor domains were studied using fluorescent ATP analogue, NBD-ATP. The binding of the NBD-ATP to the ATPase site and release from the site were monitored by the change of fluorescence intensity. The kinetic parameters of D04 and L05 were compared with other related kinesins. The kinetic parameters of D04 and L05 were apparently different form that of conventional kinesin. These kinesin may be classified into different subfamily from kinesin 1 .

2P-171 $F_{1}$-ATPase 回転モーターの角度依存的ヌクレオチドアフィニティ Angle Dependence of the Affinity for Nucleotides in Rotary Motor $F_{1}$-ATPase.

Kengo Adachi (1), Kazuhiro Oiwa (2), Takayuki Nishizaka (3), Hiroyuki Noji (4), Hiroyasu Itoh (5), Masasuke Yoshida (6), Kazuhiko Kinosita, Jr. (1) (1:Dept Physics, Waseda Univ; 2:Kobe Adv ICT Res Cnt, NiCT; 3:Dept Physics, Gakushuin Univ; 4:ISIR, Osaka Univ; 5:Tsukuba Res Lab, Hamamatsu Photonics; 6:Chem Resources Lab, Tokyo Inst Tech)

$F_{1}$-ATPase is a rotary molecular motor in which a central $\gamma$ subunit rotates against hexagonally arranged subunits $\alpha_{3} \beta_{3}$. Three $\beta$-subunits, each hosting a catalytic site, hydrolyze ATP sequentially to power the rotation of $\gamma$, whereas they synthesize ATP from ADP and inorganic phosphate when $\gamma$ rotates in reverse under an external force. To see how the catalytic sites change their properties upon rotation, we have measured the angle dependence of nucleotide affinity at single-molecule level. The angle of $\gamma$ was controlled by attaching magnetic beads to the $\gamma$ subunit and applying a rotary magnetic field. Simultaneously, binding/release of a fluorescent nucleotide (Cy3-ATP or -ADP) in a single molecule of $F_{1}$ was observed with TIRF microscopy. With Cy3-ATP and unlabeled ATP, the angle between binding and release of Cy3-ATP during continuous hydrolysis rotation was $\sim 240^{\circ}$ on average. The probability of binding was maximal $\sim 30^{\circ}$ past an ATP-waiting angle (all angles are measured in the hydrolysis direction). During synthesis rotation, binding of Cy3-ATP was most frequent $\sim 40^{\circ}$ past an ATP-waiting angle, and release was observed after about $-70^{\circ}$ of rotation. Cy3-ADP, in contrast, was bound mostly $60^{\circ} \sim 90^{\circ}$ past an ATP-waiting angle both in hydrolysis and synthesis rotations in the absence of phosphate. The release occurred after $\pm 210^{\circ}$ of rotation in either direction. In the presence of phosphate, Cy3-ADP was bound at $30^{\circ} \sim 10^{\circ}$, and the angle between binding and release was $\pm 240^{\circ}$.

\section{$2 \mathrm{P}-172$ ミオシン 5 の高速 1 分子イメージング}

Single myosin V tracking with improved time resolution

So Nishikawa (1), Mitsuhiro Sugawa(1), Hiroshi Ueno(2), Atsuko H. Iwane(1) and Toshio Yanagida(1).(1: Frontier Biosciences, Osaka Univ,; 2: ISIR, Osaka

Myosin $\mathrm{V}$ moves along the actin filament in a hand-over-hand manner with a step-size of $37 \mathrm{~nm}$. A rapid stepping transition includes quick release of a rear head from the actin molecule and a $74 \mathrm{~nm}$ long forward movement before a strong rebinding occurs again. Recent measurements using scanning probe microscopy have exhibited $5.5 \mathrm{~nm}$ sub-steps in the moving dynamics, suggesting that the released head may indeed interact with each actin monomer and track on one protofilament until reaching its true binding site (T.Okada et al 2007). However little is known on the details of this rapid stepping transition because of short dwell times.

Here we report the direct observation of the rear head dynamics with microsecond time resolution using a dark-field imaging microscopy. We used 40 $\mathrm{nm}$ gold nanoparticles, which have a strong signal to provide enough photons and response time within the given observation time. We observed large $49 \mathrm{~nm}$ and 25 $\mathrm{nm}$ intermediate steps which is similar to the value previously reported (A.R. Dunn 2007), but so far did not detect $5.5 \mathrm{~nm}$ steps in spite of our microscopy performance (spatial resolution of $\sim 2 \mathrm{~nm}$ ). In order to detect the $5.5 \mathrm{~nm}$ sub-steps clearly(e.g. abolition of measurements near the limit of the instrument performance, and by-eye data selection), we are currently working on the further improvements of the stiffness between Myosin and gold probes and will repor our latest achievements at the time of the meeting.

\section{P-173 荷電粒子の 1 次元ブラウン運動は微小管の電荷分布にどのように 影響されるか?}

How does the charge distribution of microtubules affect the one-dimensional Brownian motion of charged particles?

Itsushi Minoura, Seiichi Uchimura, Etsuko Muto (RIKEN Brain Science Institute)

The repetitive weak and strong binding cycle of motor proteins with tubulin is 